\title{
Correction to: Comprehensive Approach for Monitoring Human Tissue Degradation
}

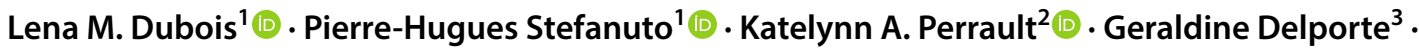 \\ Philippe Delvenne ${ }^{3}$. Jean-François Focant ${ }^{1}$ (I)
}

Published online: 24 April 2019

(c) Springer-Verlag GmbH Germany, part of Springer Nature 2019

\section{Correction to: Chromatographia \\ https://doi.org/10.1007/s10337-019-03710-3}

In the original version of this article the assignment of Figs. 6, 9 and 12 to the legends was wrong. The correct assignments of these figures and legends are shown below.
The original publication of the article has been updated to reflect the change.

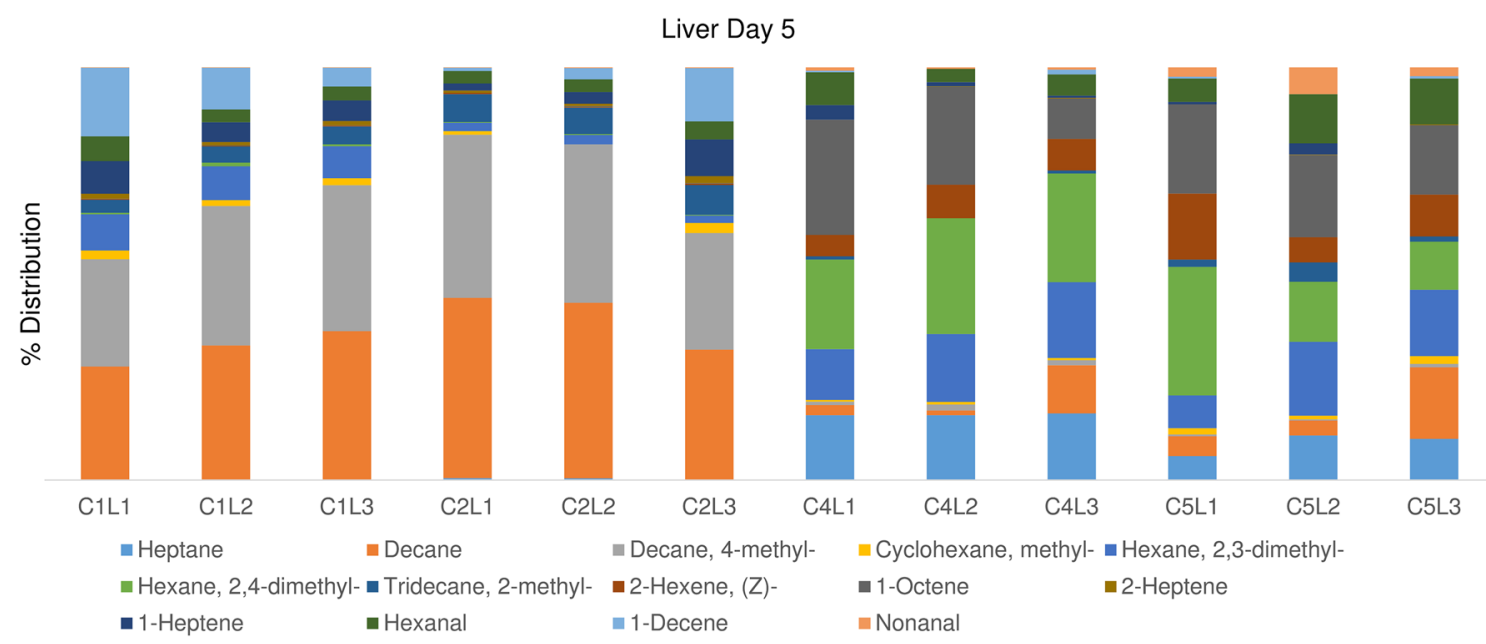

Fig. 6 Bar charts based on peak areas, normalized using probabilistic quotient normalization (PQN), providing detailed volatile organic compound (VOC) distribution of each liver sample on day 5 of decomposition. $C$ cadaver, $L$ liver

The original article can be found online at https://doi.org/10.1007/ s10337-019-03710-3.

Lena M. Dubois

lena.dubois@uliege.be

1 CART, Organic and Biological Analytical Chemistry Group, University of Liège, Allée du six Août, B6c, Quartier Agora 11, Sart-Tilman, 4000 Liège, Belgium

2 Laboratory of Forensic and Bioanalytical Chemistry, Forensic Sciences Unit, Chaminade University of Honolulu, 3140 Waialae Ave, Honolulu, HI 96816, USA

3 Pathological Anatomy and Cytology Laboratory, University of Liège, CHU B23, 4000 Liège, Belgium 


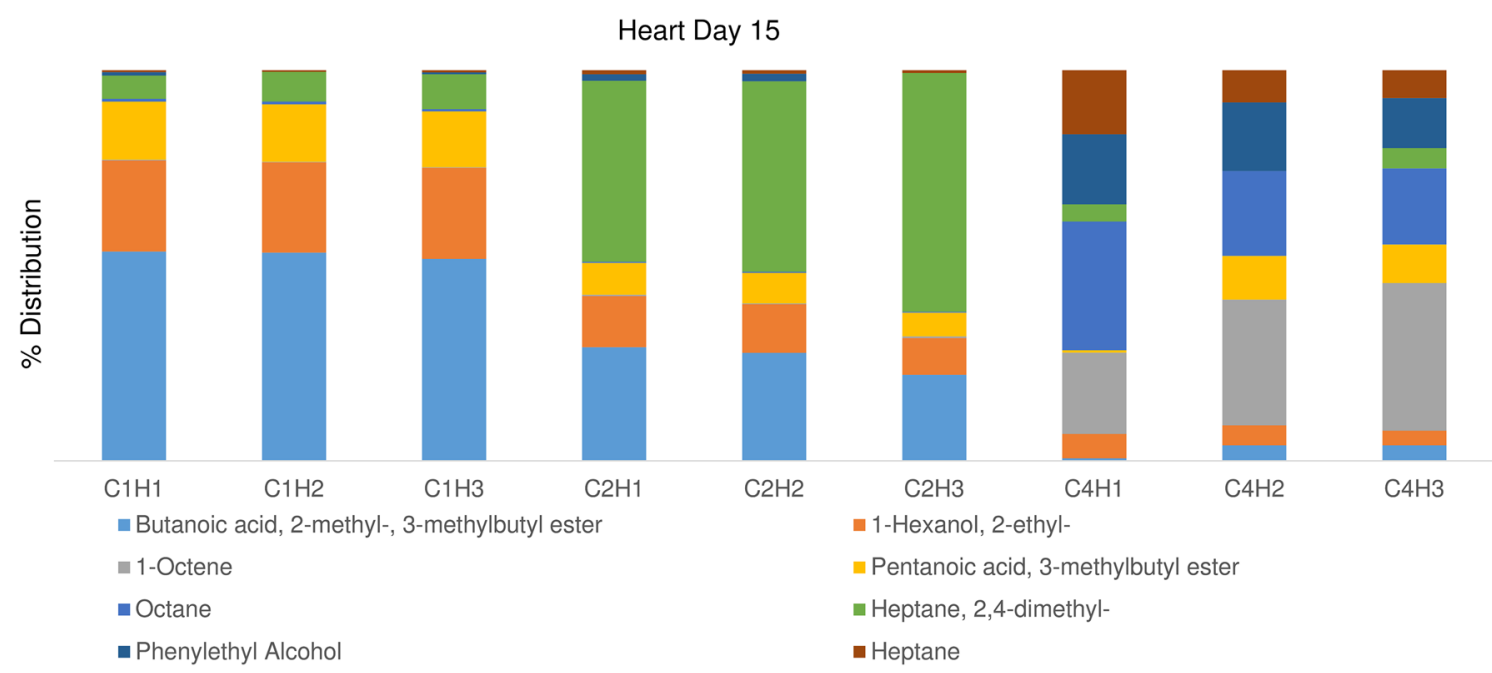

Fig. 9 Bar charts based on peak areas, normalized using probabilistic quotient normalization (PQN), displaying the volatile organic compound (VOC) distribution of heart tissue samples on day 15. $C$ cadaver, $H$ heart

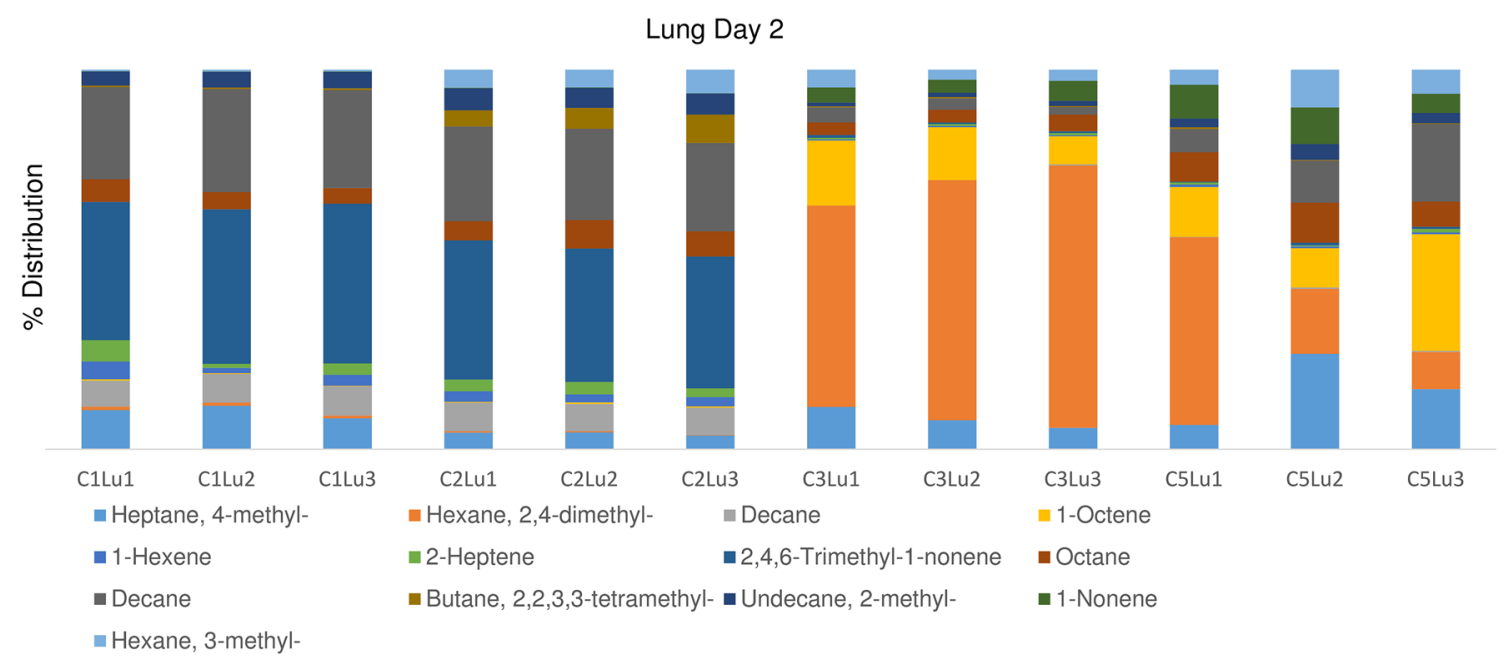

Fig. 12 Bar charts based on peak areas, normalized using probabilistic quotient normalization (PQN), displaying the volatile organic compound (VOC) distribution of lung tissue samples on day 2. $C$ cadaver, $\mathrm{Lu}$ lung 